\title{
Effects of Femtosecond Laser-Assisted Cataract Surgery on Macular and Choroidal Thickness in Diabetic Patients
}

\author{
Ling-Yun Ma $\cdot$ Ao Rong $\cdot$ Yi Jiang $\cdot$ Shu-Ya Deng
}

Received: October 22, 2020 / Accepted: December 15, 2020 / Published online: January 19, 2021

(C) The Author(s) 2021, Corrected publication 2021

\section{ABSTRACT}

Introduction: This study aimed to compare the short-term changes in retinal and choroid thickness in diabetic patients after femtosecond laser-assisted cataract surgery (FLACS) and phacoemulsification (PE) surgery.

Methods: A total of 47 eyes in the PE group and 44 eyes in the FLACS group were included. All patients underwent measurement of central macular thickness (CMT) and subfoveal choroidal thickness (SFCT) before and after surgery using optical coherence tomography (OCT).

Results: The effective phaco time (EPT) in the FLACS group was significantly reduced. The BCVA differed significantly between the two groups at 1 week and 1 month after surgery. The CMT in both groups increased at 1 week after

L.-Y. Ma · A. Rong (ه) - S.-Y. Deng

Department of Ophthalmology, Tongji Hospital Affiliated to Tongji University, Shanghai 200065, China

e-mail: rongao@163.com

A. Rong · Y. Jiang

Shanghai Xin Shi Jie Eye Hospital, Shanghai 200050, China the operation. It did not return to the preoperative level until month 12 in the PE group. In the FLACS group, the CMT began to decrease at month 3 and recovered to the preoperative level at month 12. The SFCT of the two groups increased at week 1 ; it began to decrease at month 6 in the PE group but did not recover to the preoperative level until month 12 . The SFCT in the FLACS group recovered to preoperative levels at month 6 . In the PE group, baseline CMT values predicted CMT change at week 1 and months 1, 3 and 12 after surgery. In the FLACS group, baseline CMT predicted CMT changes at week 1 , month 1 and month 3 . In the FLACS group, EPT predicted SFCT change at month 3.

Conclusion: FLACS is safe and effective in patients with no fundus change or mild diabetic retinopathy. It has advantages in effectively reducing EPT, achieving good vision earlier and promoting faster recovery of the retinal and choroidal thickness. Preoperative CMT is a significant predictor of CMT changes in the early period after FLACS.

Keywords: Cataract; Diabetic retinopathy; Femtosecond laser; Optical coherence tomography; Phacoemulsification 


\section{Key Summary Points}

\section{Why carry out this study?}

The question of whether femtosecond laser-assisted cataract surgery (FLACS) has an effect on the fundus has been a focus of clinical research.

From this perspective, we conducted a short-term assessment of the changes in central macular thickness (CMT) and subfoveal choroidal thickness (SFCT) in diabetic patients after phacoemulsification (PE) surgery and FLACS combined with intraocular lens (IOL) implantation.

\section{What was learned from the study?}

Both FLACS and traditional PE surgery caused an increase in CMT and SFCT at week 1 to month 3 after surgery.

The CMT and SFCT in the FLACS group recovered to the preoperative level earlier than the PE group.

Baseline CMT was an important predictor of postoperative CMT changes in both groups.

The BCVA in the FLACS group was batter than that in PE group at week 1 to month 3 after surgery.

\section{DIGITAL FEATURES}

This article is published with digital features, including a summary slide, to facilitate understanding of the article. To view digital features for this article go to https://doi.org/10.6084/ m9.figshare.13379597.

\section{INTRODUCTION}

According to data published by the International Diabetes Federation, the number of adults with diabetes worldwide was predicted to reach approximately 463 million in 2019, and was expected to increase to 700 million by 2045. Diabetes mellitus (DM) can destroy the blood-retinal barrier $[1,2]$ and cause pathological changes in the retina [3], known as diabetic retinopathy (DR). Data from 35 studies in the United States, Australia, Europe and Asia show that the overall prevalence of DR in diabetic patients is $34.6 \%$, and the prevalence of proliferative diabetic retinopathy (PDR) is $7.0 \%$ [4].

In addition, diabetes mellitus increases the risk of cataracts, especially at younger ages, and the turbidity of the lens hinders visualization of the patient's retina during funduscopy $[5,6]$. The presence of cataract was also found to be the most significant risk factor for visual impairment in diabetic patients $[7,8]$. It is estimated that up to $20 \%$ of cataract surgeries are performed in patients with diabetes mellitus [9-11]. Therefore, cataract surgery is essential to restore vision in these patients and to diagnose and monitor the development of DR.

Phacoemulsification (PE) surgery can cause an increase in inflammatory factors such as IL-6 and prostaglandin in the anterior chamber and vitreous body. Simultaneously, the heat, radiation and shock generated by PE have a greater influence on the vitreous and fundus [12, 13]. After the operation, some diabetic patients have an accelerated course of fundus microangiopathy [14], retinal thickening [15] and choroidal thickening, with different changes shown among studies [16, 17]. Researchers have confirmed that femtosecond laser-assisted cataract surgery (FLACS) can optimize PE parameters [18], reduce the cumulative release of ultrasound energy [19] and reduce complications $[20,21]$. However, it is worth noting that FLACS requires suction of the cornea, and so the intraocular pressure is increased significantly during capsulotomy and fragmentation [22]. Some scholars believe that FLACS causes more serious inflammation and increases the incidence of complications [23]. 
Therefore, whether FLACS has an effect on the fundus has been the focus of clinical research. Especially for diabetic patients with strong postoperative inflammatory response and who are prone to macular edema, whether FLACS is safe and effective requires further research evidence. From this perspective, we conducted a short-term assessment of the changes in central macular thickness (CMT) and subfoveal choroidal thickness (SFCT) of diabetic patients after PE surgery and FLACS combined with intraocular lens (IOL) implantation.

\section{METHODS}

\section{Patients}

This prospective study recruited 91 diabetic patients (91 eyes) undergoing PE surgery or FLACS combined with IOL implantation in Shanghai Xin Shi Jie Eye Hospital (China). The study complied with the Declaration of Helsinki of 1964 and its later amendments. The study was reviewed and approved by the Shanghai Xin Shi Jie Eye Hospital ethics committee. All patients understood and provided written informed consent. All patients had been diagnosed with diabetes mellitus and were currently being treated with orally administered drugs or insulin injections. Fasting blood glucose was controlled at $4.4-10 \mathrm{mmol} / \mathrm{L}$ and $\mathrm{HbA1c}(\%)$ was less than $8 \%$ before surgery. Patients were diagnosed as having no diabetic retinopathy (NoDR) or mild non-proliferative diabetic retinopathy (NPDR) according to the International Clinical Disease Severity Scale for DR. The first eye was enrolled if the patient underwent surgery for both eyes. Patients with DR of other stages, macular edema, other ocular diseases or history of ocular surgery, long-term local or systemic application of steroid drugs, preoperative lens opacity obviously making it difficult to obtain optical coherence tomography (OCT) scan images, diopter $>-6.00 \mathrm{D}$ or axial length $>26.0 \mathrm{~mm}$, and patients with severe hypertension, smoking or alcoholism were excluded. The patients were divided into two groups according to patient preference; the $\mathrm{PE}$ group underwent PE surgery combined with
IOL implantation, and the FLACS group underwent FLACS combined with IOL implantation.

\section{Patient Assessment}

Best-corrected visual acuity (BCVA) was examined using the Snellen decimal scale and then converted to the logarithm of the minimal angle of resolution (logMAR) scale. Intraocular pressure was measured using a noncontact technique (FT-1000 tonometer; TOMEY Corporation, Nagoya, Japan). In addition, all patients underwent slit-lamp examination (SL-3G, Topcon Corporation, Tokyo, Japan), diopter (CT-80, Topcon), axial length (IOLMaster 500; Carl Zeiss Meditec Inc, Jena, Germany), wide-angle fundus photography (Daytona p200T, Optos plc, Dunfermline, UK), and macular and optic nerve examination before the operation to exclude other eye diseases. Based on the results of slitlamp examination at maximum illumination without light filtering, the Lens Opacities Classification System (LOCS) III was used to grade the lens severity. BCVA, slit-lamp examination, intraocular pressure, wide-angle fundus photography and OCT examination were performed at 1 week and 1, 3, 6 and 12 months after surgery.

\section{OCT}

The same professional examiner used OCT (Cirrus HD-OCT 5000; Carl Zeiss Meditec, Inc., Dublin, CA, USA) to scan the macula with the macular cube $512 \times 128$ combo mode to automatically measure the CMT. SFCT was measured using the enhanced depth imaging (EDI) mode of the OCT (Spectralis HD-OCT; Heidelberg Engineering $\mathrm{GmbH}$, Heidelberg, Germany). Under posterior segment tracking, 100 frames were captured and averaged to compose an A-scan; each EDI-OCT image had 768 A-scans. Using the sections through the center of the macula, the distance from the hyperreflective band corresponding to Bruch's membrane under the foveola to the choroid-sclera junction was measured using the instrument's software. The same experienced retinal expert 
carried out three measurements manually and took the average of the three. The examiner and the vitreoretinal doctor were unaware of the identity of patients at all times. All OCT examinations were conducted from 9 to 11 a.m. after pupil dilation.

\section{Surgery}

All surgeries were performed by the same experienced surgeon. All patients were given 0.5\% levofloxacin eye drops (Cravit; Santen Pharmaceutical Co., Japan) to prevent infections, and patients in the FLACS group were also given diclofenac sodium (Shenyang Sinqi, China) 3 days before surgery. Combination tropicamide and phenylephrine hydrochloride eye drops (Mydrin-P; Santen Pharmaceutical Co., Japan) were used for mydriasis $60 \mathrm{~min}$ before surgery, and $0.4 \%$ oxybuprocaine eye drops (Benoxil; Santen Pharmaceutical Co., Japan) were used for topical anesthesia.

In the FLACS group, the surgeon used the same LenSx Laser system (Alcon Laboratories Inc., Fort Worth, TX, USA) to perform the capsulotomy and fragmentation, with laser pulse energy of $5 \mathrm{~mJ}$. Both groups used the same Infiniti system (Alcon Laboratories Inc., Fort Worth, TX, USA) for PE. After removing the cortex, the folded posterior chamber IOL (Rayner Intraocular Lenses Limited or HumanOptics AG) was implanted into the capsular bag, and the effective phaco time (EPT) was recorded. Postoperative drugs were $0.5 \%$ levofloxacin eye drops (Cravit Ophthalmic Solution; Santen Pharmaceutical Co., Ltd,, Japan) and tobramycin dexamethasone eye drops (Tobradex; S.A. Alcon-Couvreur N.V., Belgium), one drop four times a day for 2 weeks; the two groups were the same. Then the steroid drops were decreased to twice a day for a week.

\section{Statistical Analysis}

All data were statistically analyzed using SPSS 25.0 software (IBM Corp., Armonk, NY, USA). Mean \pm standard deviation was used to describe the continuous variable of normal distribution, and non-normally distributed variables were expressed as median (interquartile range [IQR]). The $t$ test was used to compare the normally distributed variables, the Wilcoxon test was used to compare the non-normally distributed variables, and the chi-square test was used to compare the measurement data. A multiple linear regression model was used to analyze the impact of the baseline parameters on the changes in CMT and CT versus baseline. $P<0.05$ was considered to indicate a significant difference.

\section{RESULTS}

\section{Characteristics}

In total, 47 people (47 eyes) were followed up in the PE group, including 19 men and 28 women, and five patients were lost to follow-up. The average age of the patients in the PE group was $69.32 \pm 6.24$ (range 54-83) years. The FLACS group completed 44 follow-ups (44 eyes), including 26 men and 18 women, and three patients were lost to follow-up. The average age of the patients in the FLACS group was $70.77 \pm 7.24$ (range 53-85) years (Table 1).

No serious complications occurred during or after the operation. No patient developed pseudophakic cystoid macular edema (PCME) or subretinal fluid. There was no significant difference in age $(P=0.307)$, diabetic history $(P=0.454)$, HbA1c $(\%) \quad(P=0.544)$, anterior chamber depth $(P=0.792)$, lens grade $(P=0.827)$, ametropia $(P=0.243)$, axial length $(P=0.781)$, intraocular pressure $(P=0.118)$, BCVA $(P=1.000)$, CMT $(P=0.256)$ or SFCT $(P=0.318)$ between the two groups. The EPT in the PE group was $6.60 \mathrm{~s}(5.20-7.70 \mathrm{~s})$, whereas it was $2.34 \pm 0.80 \mathrm{~s}$ in the FLACS group, which was a significant decrease $(P=0.000)$ (Table 1$)$.

\section{BCVA}

The BCVA before and after surgery is shown in Table 2. A significant difference was observed between the two groups 1 week and 1 month after operation $(P<0.05)$. In both groups, the difference between the baseline and 
postoperative BCVA was statistically significant $(P<0.05)$ (Table 2).

\section{Preoperative and Postoperative CMT}

The CMT before and after operation is shown in Table 2. No significant differences were found between the two groups at baseline or any postoperative follow-up points $(P>0.05)$. In the PE group, the difference between the baseline and postoperative CMT values was statistically significant at all time points $(P<0.05)$, and the same was true in the FLACS group except at month $12(P=0.859)$ (Tables 2,3$)$.

\section{Preoperative and Postoperative SFCT}

The SFCT values before and after operation are shown in Table 2. The difference in SFCT between the two groups was statistically significant only at postoperative month 12 $(P=0.033)$. A significant difference between the baseline and postoperative SFCT values was observed in the PE group $(P<0.05)$. Compared to the baseline SFCT, postoperative SFCT was significantly different in the FLACS group $(P<0.05)$ at week 1 and months 1 and 3 . No significant difference in SFCT was observed between baseline and month 6 or 12 after operation in the FLACS group $(P>0.05)$ (Tables 2, 3; Fig. 1).

\section{Multiple Linear Regression Analysis of the PE Group}

In the PE group, baseline CMT predicted postoperative CMT at week 1 and months 1, 3 and 12 (Table 4). EPT predicted SFCT at month 3 (Table 5).

\section{Multiple Linear Regression Analysis of the FLACS Group}

In the FLACS group, baseline CMT values predicted CMT at week 1, month 1 and month 3 (Table 4). Ametropia predicted SFCT at month 12 (Table 5).

\section{DISCUSSION}

Ocular microcirculation dysfunction caused by diabetes mellitus can affect the retinal blood supply, causing hypoxia and destruction of the

Table 1 Characteristics of the PE and FLACS groups

\begin{tabular}{llll}
\hline & PE group $(\boldsymbol{n}=\mathbf{4 7})$ & FLACS group $(\boldsymbol{n}=\mathbf{4 4})$ & $\boldsymbol{P}$ value \\
\hline Male/female & $19 / 28$ & $26 / 18$ & 0.075 \\
Age (years) & $69.32 \pm 6.24$ & $70.77 \pm 7.24$ & 0.307 \\
Diabetic history (years) & $8.00(4.00-12.00)$ & $9.00(5.00-14.50)$ & 0.454 \\
HbAlc (\%) & $6.89 \pm 0.68$ & $6.97 \pm 0.53$ & 0.544 \\
Anterior chamber depth $(\mathrm{mm})$ & $2.93 \pm 0.27$ & $2.92 \pm 0.23$ & 0.792 \\
Lens grade & $3.00(3.00-3.00)$ & $3.00(3.00-3.00)$ & 0.827 \\
Ametropia (diopter) & $-1.38 \pm 1.91$ & $-0.89 \pm 2.08$ & 0.243 \\
Axial length (mm) & $23.40(22.80-23.90)$ & $23.30(22.73-23.90)$ & 0.781 \\
Intraocular pressure (mmHg) & $16.70 \pm 2.60$ & $17.50 \pm 2.24$ & 0.118 \\
BCVA (logMAR) & $0.60(0.40-0.80)$ & $0.65(0.40-0.95)$ & 1.000 \\
Effective phaco time $(\mathrm{s})$ & $6.60(5.20-7.70)$ & $2.34 \pm 0.80$ & $0.000^{*}$ \\
\hline
\end{tabular}

*Indicates statistically significant values 


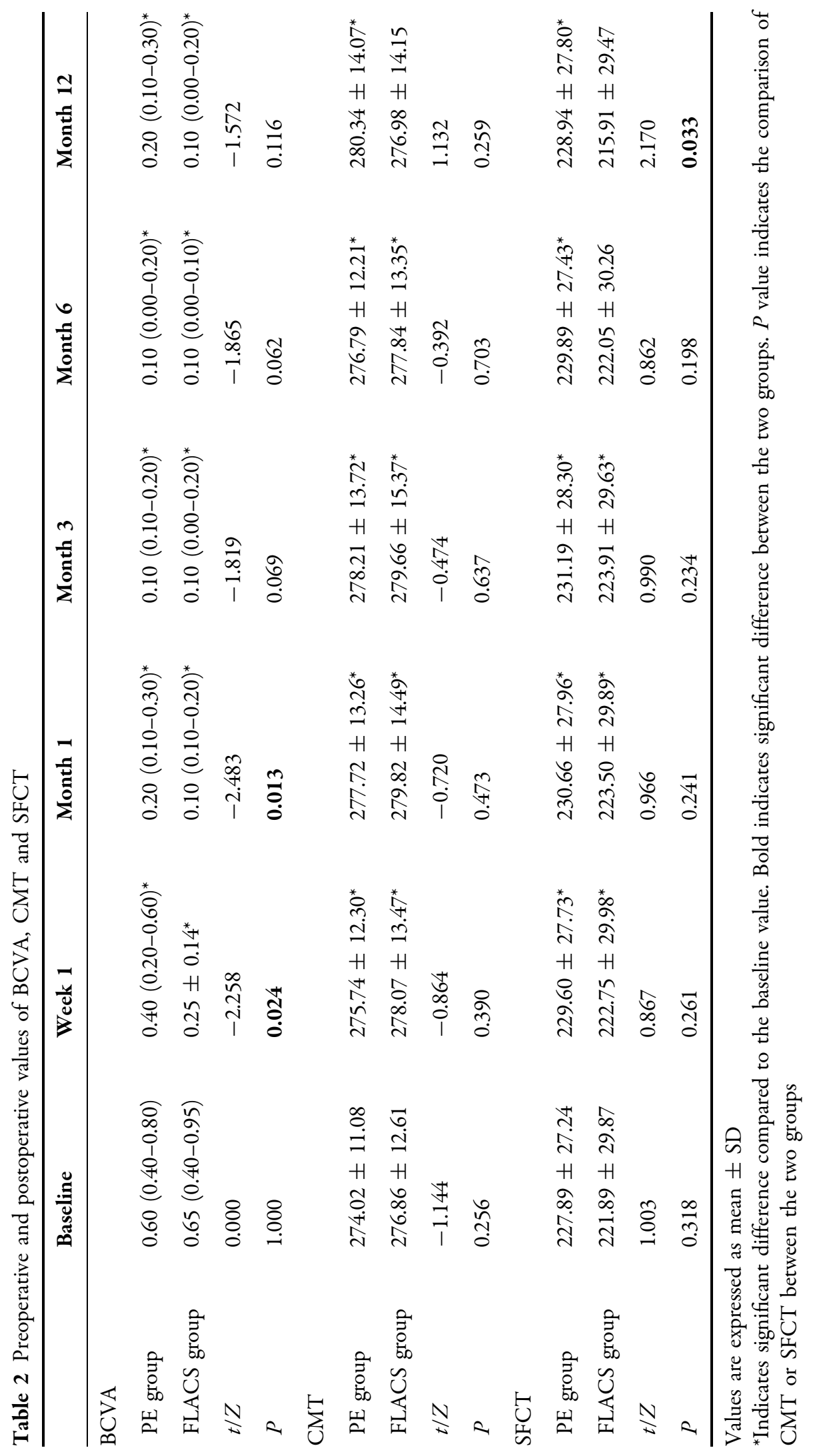


Table 3 Paired-samples test of postoperative CMT and SFCT compared with baseline

\begin{tabular}{llll}
\hline & PE group & & FLACS group \\
\cline { 2 - 3 }$P$ value & & $P$ value \\
\hline
\end{tabular}

CMT

$\begin{array}{lllll}\text { Basal-Week 1 } & -1.723 & 0.000^{*} & -1.205 & 0.000^{*} \\ \text { Basal-Month 1 } & -3.702 & 0.000^{*} & -2.955 & 0.000^{*} \\ \text { Basal-Month 3 } & -4.191 & 0.000^{*} & -2.795 & 0.000^{*} \\ \text { Basal-Month 6 } & -2.766 & 0.000^{*} & -0.977 & 0.001^{*} \\ \text { Basal-Month 12 } & -6.319 & 0.000^{*} & -0.114 & 0.859\end{array}$

SFCT

\begin{tabular}{lllll} 
Basal-Week 1 & -1.702 & $0.000^{*}$ & -0.864 & $0.006^{*}$ \\
Basal-Month 1 & -2.766 & $0.000^{*}$ & -1.614 & $0.000^{*}$ \\
Basal-Month 3 & -3.298 & $0.000^{*}$ & -2.023 & $0.000^{*}$ \\
Basal-Month 6 & -2.000 & $0.000^{*}$ & -0.159 & 0.582 \\
Basal-Month 12 & -1.043 & $0.022^{*}$ & 5.977 & $0.000^{*}$ \\
\hline
\end{tabular}

${ }^{*}$ Indicates statistically significant values

retinal barrier. Even in NoDR patients who have no significant decrease in vision and no observable changes in diabetic retinopathy at the fundus, auxiliary examination may still reveal that the blood flow of the macula and the optic disc has changed [24]. Inflammatory reactions caused by cataract surgery, ultrasound power and the intraoperative photostress from microscopic light will affect the fundus of these patients. Multiple studies have shown that CMT in diabetic patients increases after PE surgery [25-27]. In particular, the incidence of macular edema in patients with moderate and severe NPDR increased significantly [28].

However, existing studies have confirmed that the microcirculation disorder caused by diabetes mellitus is not limited to the retina, and also affects the choroidal microcirculation, causing the choroidal blood supply to decrease $[29,30]$, and the choroid thickness decreases compared with that in normal individuals [31-33]. The choroid has the role of providing nutrition and oxygenation to the retinal pigment epithelium layer and the outer retina layer. The dysfunctional choroid also affects the retinal function and plays an important role in the development of DR [17]. Therefore, the use the retina and choroid parameters to observe fundus changes in diabetic patients after cataract surgery is more comprehensive. Because of the dense choroidal vessels in the fovea, SFCT was used as the choroid evaluation parameter and CMT was used as the macular evaluation parameter in this study. In order to ensure safety, the study excluded patients with moderate to severe NPDR and PDR whose microvascular damage was more severe.

The FLACS surgical method has the advantages of assisting capsulotomy and fragmentation, and shortening the surgeon's learning
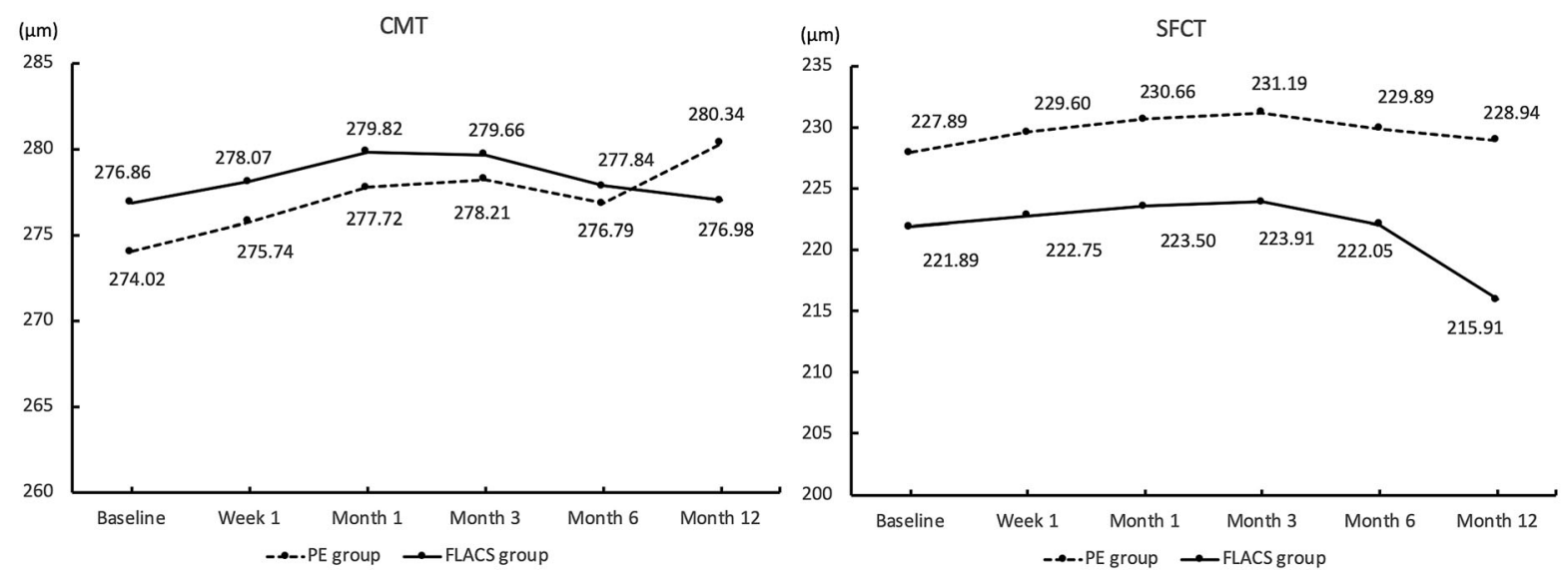

Fig. 1 Trends of postoperative CMT and SFCT 
Table 4 Multiple linear regression analysis of postoperative CMT change compared with baseline

\begin{tabular}{|c|c|c|c|c|c|c|c|c|c|c|}
\hline & \multicolumn{5}{|c|}{ PE group $P$ value } & \multicolumn{5}{|c|}{ FLACS group $P$ value } \\
\hline & $\begin{array}{l}\text { Week } \\
1\end{array}$ & $\begin{array}{l}\text { Month } \\
1\end{array}$ & $\begin{array}{l}\text { Month } \\
3\end{array}$ & $\begin{array}{l}\text { Month } \\
6\end{array}$ & $\begin{array}{l}\text { Month } \\
12\end{array}$ & $\begin{array}{l}\text { Week } \\
1\end{array}$ & $\begin{array}{l}\text { Month } \\
1\end{array}$ & $\begin{array}{l}\text { Month } \\
3\end{array}$ & $\begin{array}{l}\text { Month } \\
6\end{array}$ & $\begin{array}{l}\text { Month } \\
12\end{array}$ \\
\hline Age & 0.260 & 0.129 & 0.104 & 0.750 & 0.197 & 0.298 & 0.330 & 0.704 & 0.099 & 0.698 \\
\hline Gender & 0.109 & 0.431 & 0.238 & 0.531 & 0.402 & 0.281 & 0.296 & 0.194 & 0.500 & 0.311 \\
\hline $\begin{array}{r}\text { Diabetic } \\
\text { history }\end{array}$ & 0.379 & 0.819 & 0.954 & 0.056 & 0.584 & 0.358 & 0.537 & 0.440 & 0.341 & 0.646 \\
\hline HbAlc (\%) & 0.653 & 0.789 & 0.914 & 0.963 & 0.179 & 0.967 & 0.605 & 0.050 & 0.146 & 0.711 \\
\hline Basal-BCVA & 0.517 & 0.602 & 0.206 & 0.469 & 0.874 & 0.674 & 0.297 & 0.055 & 0.086 & 0.762 \\
\hline Basal-IOP & 0.713 & 0.755 & 0.339 & 0.057 & 0.305 & 0.516 & 0.466 & 0.201 & 0.082 & 0.452 \\
\hline EPT & 0.717 & 0.993 & 0.608 & 0.939 & 0.994 & 0.785 & 0.679 & 0.890 & 0.662 & 0.858 \\
\hline Ametropia & 0.397 & 0.408 & 0.245 & 0.961 & 0.593 & 0.416 & 0.618 & 0.870 & 0.154 & 0.754 \\
\hline Axial length & 0.157 & 0.881 & 0.710 & 0.194 & 0.278 & 0.056 & 0.634 & 0.563 & 0.967 & 0.737 \\
\hline Basal-CMT & $0.005^{*}$ & $0.001^{*}$ & $0.004^{*}$ & 0.192 & $0.009^{*}$ & $0.002^{*}$ & $0.001^{*}$ & $0.000^{*}$ & 0.951 & 0.170 \\
\hline
\end{tabular}

*Indicates statistically significant values

Table 5 Multiple linear regression analysis of postoperative SFCT change compared with baseline

\begin{tabular}{|c|c|c|c|c|c|c|c|c|c|c|}
\hline & \multicolumn{5}{|c|}{ PE group $P$ value } & \multicolumn{5}{|c|}{ FLACS group $P$ value } \\
\hline & $\begin{array}{l}\text { Week } \\
1\end{array}$ & $\begin{array}{l}\text { Month } \\
1\end{array}$ & $\begin{array}{l}\text { Month } \\
3\end{array}$ & $\begin{array}{l}\text { Month } \\
6\end{array}$ & $\begin{array}{l}\text { Month } \\
12\end{array}$ & $\begin{array}{l}\text { Week } \\
1\end{array}$ & $\begin{array}{l}\text { Month } \\
1\end{array}$ & $\begin{array}{l}\text { Month } \\
3\end{array}$ & $\begin{array}{l}\text { Month } \\
6\end{array}$ & $\begin{array}{l}\text { Month } \\
12\end{array}$ \\
\hline Age & 0.492 & 0.572 & 0.728 & 0.190 & 0.943 & 0.093 & 0.135 & 0.362 & 0.341 & 0.652 \\
\hline Gender & 0.623 & 0.325 & 0.587 & 0.302 & 0.063 & 0.773 & 0.762 & 0.338 & 0.632 & 0.298 \\
\hline $\begin{array}{l}\text { Diabetic } \\
\text { history }\end{array}$ & 0.515 & 0.461 & 0.344 & 0.231 & 0.424 & 0.315 & 0.677 & 0.183 & 0.584 & 0.351 \\
\hline HbAlc (\%) & 0.641 & 0.879 & 0.282 & 0.488 & 0.920 & 0.428 & 0.738 & 0.372 & 0.606 & 0.597 \\
\hline Basal-BCVA & 0.177 & 0.984 & 0.265 & 0.854 & 0.641 & 0.667 & 0.669 & 0.723 & 0.069 & 0.732 \\
\hline Basal-IOP & 0.120 & 0.617 & 0.417 & 0.479 & 0.356 & 0.081 & 0.192 & 0.067 & 0.082 & 0.554 \\
\hline EPT & 0.109 & 0.592 & $0.033^{*}$ & 0.395 & 0.129 & 0.420 & 0.518 & 0.087 & 0.260 & 0.796 \\
\hline Ametropia & 0.158 & 0.596 & 0.381 & 0.466 & 0.051 & 0.368 & 0.262 & 0.311 & 0.425 & $0.031^{*}$ \\
\hline Axial length & 0.857 & 0.233 & 0.135 & 0.186 & 0.971 & 0.690 & 0.443 & 0.344 & 0.225 & 0.276 \\
\hline Basal-CMT & 0.089 & 0.148 & 0.133 & 0.197 & 0.347 & 0.110 & 0.088 & 0.080 & 0.829 & 0.456 \\
\hline
\end{tabular}

${ }^{*}$ Indicates statistically significant values 
curve. Nagy et al. confirmed that although edema of the outer nuclear layer of the macula occurred after surgery with both methods, it was lighter in the femtosecond laser group [34]. In addition, no change was observed in choroidal thickness at month 1 after FLACS compared with the baseline [35]. However, femtosecond laser pulse shockwave can cause mechanical damage to anterior segment structures such as the iris and ciliary body, and microbubbles generated by femtosecond laser action can also mediate the inflammatory cascade. Compared with conventional PE surgery, FLACS led to a more significant increase in prostaglandin levels [14]. In addition, the melanosomes of the retinal pigment epithelium layer have a strong absorption effect on nearinfrared laser light, and this effect may cause damage to the retina and choroid. Whether the increase in intraocular pressure caused by FLACS affects the blood supply of the retina and optic nerve has been a focus of research.

At present, there are many studies focused on the changes in retinal and choroidal thickness in diabetic patients after PE operation. Many scholars are skeptical about whether the FLACS application in diabetic patients is safe and effective, and whether it affects the retina and choroid. Therefore, this study will expand this discussion.

BCVA was effectively improved in both groups from week 1 after surgery, but a statistically significant difference in BCVA between the two groups was observed only in the early postoperative period. The cumulative dissipated energy (CDE) in the FLACS group was significantly lower than that in the PE group $(P<0.0001)$, which means less damage to surrounding structures and shorter recovery time $[36,37]$. Wei et al. [38] used the Corvis ST to confirm that the effect of FLACS on corneal biomechanics was smaller than that of PE at week 1 and month 1 . A prospective randomized intraindividual cohort study also confirmed that FLACS can lower the risk of corneal edema [39]. This may be the reason that BCVA was better in the FLACS group than in the PE group in the early postoperative period. A case-control study by Cavallini et al. [40] confirmed that a significant improvement in average BCVA was observed at month 3 , but there was no statistical difference between the two groups. A metaanalysis by Kolb et al. suggested that visual acuity did not show any difference between two groups at month 1 and month 3 , and these results were not believed to carry any clinical importance [41]. Another randomized controlled trial by Day et al. [42] confirmed that the average BCVA difference between PE and FLACS was $-0.01 \log$ MAR $(P=0.34)$ at month 3 after surgery. The study by Ewe et al. confirmed that at 6 months after surgery, FLACS did not demonstrate a clinically meaningful improvement in visual outcomes over PE surgery [43]. Day et al. [44] confirmed that binocular corrected distance visual acuity (CDVA) favoring FLACS $(P=0.036)$, although statistically significant, was not clinically important.

None of the patients in the two groups of the current study experienced serious intraoperative complications such as vitreous hemorrhage or posterior capsule rupture. This may be because the surgeon in this study was experienced in cataract surgery and the LenSx Laser system. For inexperienced doctors, this may be different [45]. At the same time, the results of this study showed that the CMT and SFCT in the FLACS group recovered to the preoperative level 12 months after surgery, which also confirmed that for NoDR patients or patients with mild NPDR, FLACS is safe in its effects on retinal and choroidal thickness.

After conventional PE surgery, the risk of macular thickening in diabetic patients is increased $[46,47]$. Existing studies have reported that the central macular thickness increases in patients with mild and moderate NPDR in months 1, 3 and 6 after conventional PE [48], and there is no significant difference in the central macular thickness between baseline and post-operation in NoDR patients [49]. In this study, the postoperative CMT of both groups began to increase from week 1 after the operation and began to decline at month 3 . At month 6 , neither group had returned to preoperative levels. This is consistent with the results of Liu et al. [48]. However, after follow-up to month 12 , we found that the CMT in the FLACS group recovered to the preoperative level, while the 
CMT in the PE group had a tendency to rise again.

Postoperative inflammation caused by tissue damage from cataract surgery, breakdown of the blood-retinal and blood-aqueous barriers, and the release of prostaglandins and vascular endothelial growth factor (VEGF) are all possible mechanisms causing macular thickening $[50,51]$. Diabetic retinopathy can lead to increased permeability of retinal blood vessels and swelling of the macula [52]. Results reported by Vujosevic et al. [53] and Pierro et al. [33] confirmed the occurrence of dilated retinal superficial capillaries and pathological changes before cataract surgery in diabetic patients. Therefore, in such patients, cataract surgery has a higher risk of macular thickening. In this study, the CMT of the FLACS group recovered to the preoperative state at month 12 , but that in the PE group did not. This may prove that the surgical impact and the postoperative inflammation caused by FLACS can be resolved in a shorter time.

Regression analysis shows that the baseline CMT was the most important predictor affecting the PE group and the FLACS group within 12 months and 3 months after surgery, respectively. Therefore, for diabetic patients, the preoperative CMT level should be considered. Since the fundus capillaries of diabetic patients who have not undergone DR fundus changes can be affected, for patients with high preoperative CMT levels, whether undergoing traditional PE surgery or FLACS, close attention should be paid to the postoperative retinal thickness and retinal capillary morphology and perfusion situation. Clinicians should be alert to the rapid development of diabetic retinopathy, obvious retinal thickening and even the appearance of macular edema.

Ibrahim et al. [54], using EDI-OCT, found that SFCT was significantly increased 1 week after PE and returned to the preoperative level at month 3 after surgery. However, conflicting results have been reported in studies on postoperative SFCT changes in diabetic patients, with some studies showing that SFCT increased after PE surgery in diabetic patients $[55,56]$, while others have found no change $[57,58]$, and yet others have shown a postoperative reduction in choroidal thickness [17]. In the present study, the SFCT increased at week 1 after surgery in the PE group and began to decline at month 3 , but did not return to preoperative levels until month 12. Although a similar increase was seen in the early stage in the FLACS group, the SFCT had returned to preoperative levels 6 months after surgery.

Choroidal thickening is also related to surgical inflammatory response, the release of prostaglandins and cytokines, and the destruction of the blood-retinal barrier $[59,60]$. The earlier recovery of SFCT to preoperative levels also confirmed that FLACS has a smaller effect on intraocular inflammation. The difference in EPT between the two groups was significant, and regression analysis showed that EPT did affect the SFCT relative to baseline in month 3 in the PE group, indicating that effective control of EPT can lead to faster SFCT recovery to preoperative levels, and FLACS has an intuitive and effective role in reducing EPT.

In order to prevent myosis caused by anterior chamber inflammation as a result of femtosecond laser surgery and consequent implications for subsequent surgical operations, the FLACS group in this study was given nonsteroidal antiinflammatory eye drops before surgery. Studies have confirmed that postoperative use of nonsteroidal anti-inflammatory drugs will slow the increase in retinal and choroidal thickness [61]. Therefore, whether preoperative prophylactic use has an effect on postoperative retinal and choroidal thickness requires further study.

Our research has certain limitations. Firstly, the sample size was small and surgery was not randomly assigned to patients. The choroidal thickness was measured manually at a single point. Furthermore, the study did not include patients with moderate to severe NPDR and PDR proliferative retinopathy. Related mechanisms still need further study.

\section{CONCLUSIONS}

In our sample population, compared with traditional PE surgery, FLACS effectively reduced EPT, achieving good vision earlier and earlier recovery of retinal and choroidal thickness. 
Baseline CMT was found to be an important predictor of postoperative CMT changes in FLACS and traditional PE surgery. Further studies are needed to confirm these findings.

\section{ACKNOWLEDGEMENTS}

We thank all study participants for their involvement in the study.

Funding No funding or sponsorship was received for this study or publication of this article.

Authorship All named authors meet the International Committee of Medical Journal Editors (ICMJE) criteria for authorship for this article, take responsibility for the integrity of the work as a whole, and have given their approval for this version to be published.

Disclosures Ling-Yun Ma, Ao Rong, Yi Jiang, and Shu-Ya Deng have nothing to disclose.

Compliance with Ethics Guidelines This study complied with the Declaration of Helsinki of 1964 and its later amendments. The study was reviewed and approved by the Shanghai Xin Shi Jie Eye Hospital ethics committee. All patients understood and provided written informed consent.

Data Availability The datasets generated and analyzed during the current study are available from the corresponding author on reasonable request.

Open Access. This article is licensed under a Creative Commons Attribution-NonCommercial 4.0 International License, which permits any non-commercial use, sharing, adaptation, distribution and reproduction in any medium or format, as long as you give appropriate credit to the original author(s) and the source, provide a link to the Creative Commons licence, and indicate if changes were made. The images or other third party material in this article are included in the article's Creative Commons licence, unless indicated otherwise in a credit line to the material. If material is not included in the article's Creative Commons licence and your intended use is not permitted by statutory regulation or exceeds the permitted use, you will need to obtain permission directly from the copyright holder. To view a copy of this licence, visit http://creativecommons.org/licenses/by$\mathrm{nc} / 4.0 /$.

\section{REFERENCES}

1. Joussen AM, Poulaki V, Mitsiades N, et al. Nonsteroidal anti-inflammatory drugs prevent early diabetic retinopathy via TNF-alpha suppression[J]. FASEB J. 2002;16(1):438-40. https://doi.org/10. 1096/fj.01-0707fje.

2. Joussen AM, Poulaki V, Le ML, et al. A central role for inflammation in the pathogenesis of diabetic retinopathy[J]. FASEB J. 2004;18(10):1450-2. https://doi.org/10.1096/fj.03-1476fje.

3. Behl T, Kotwani A. Exploring the various aspects of the pathological role of vascular endothelial growth factor (VEGF) in diabetic retinopathy[J]. Pharmacol Res. 2015;99:137-48. https://doi.org/10.1016/j. phrs.2015.05.013.

4. Yau JWY, Rogers SL, Kawasaki R, et al. Global prevalence and major risk factors of diabetic retinopathy[J]. Diabetes Care. 2012;35(3):556-64. https://doi.org/10.2337/dc11-1909.

5. Harding JJ, Egerton M, Vanheyningen R, et al. Diabetes, glaucoma, sex, and cataract-analysis of combined data from 2 case control studies[J]. Br J Ophthalmol. 1993;77(1):2-6. https://doi.org/10. 1136/bjo.77.1.2.

6. Becker C, Schneider C, Aballea S, et al. Cataract in patients with diabetes mellitus-incidence rates in the UK and risk factors[J]. Eye. 2018;32(6):1028-35. https://doi.org/10.1038/s41433-017-0003-1.

7. Rani PK, Raman R, Gella L, et al. Prevalence of visual impairment and associated risk factors in subjects with type II diabetes mellitus: Sankara Nethralaya diabetic retinopathy epidemiology and molecular genetics study (SN-DREAMS, report 16)[J]. Middle East African journal of ophthalmology. 2012;19(1):129-34. https://doi.org/10.4103/ 0974-9233.92129.

8. Onakpoya $\mathrm{OH}$, Kolawole BA, Adeoye $\mathrm{AO}$, et al. Visual impairment and blindness in type 2 diabetics: Ife-Ijesa diabetic retinopathy study[J]. Int Ophthalmol. 2016;36(4):477-85. https://doi.org/10. 1007/s10792-015-0145-8. 
9. Antcliff RJ, Poulson A, Flanagan DW. Phacoemulsification in diabetics[J]. Eye. 1996;10:737-41. https://doi.org/10.1038/eye.1996.171.

10. Baker CW, Almukhtar T, Bressler NM, et al. Macular edema after cataract surgery in eyes without preoperative central-involved diabetic macular edema[J]. JAMA Ophthalmol. 2013;131(7):870-9. https://doi.org/10.1001/jamaophthalmol.2013. 2313.

11. Cetinkaya A, Yilmaz G, Akova YA. Photic retinopathy after cataract surgery in diabetic patients[J]. Retina. 2006;26(9):1021-8. https://doi. org/10.1097/01.iae.0000254895.78766.af.

12. Grzybowski A, Kanclerz P, Huerva V, et al. Diabetes and phacoemulsification cataract surgery: difficulties, risks and potential complications[J]. J Clin Med. 2019;8(5):716. https://doi.org/10.3390/ jcm8050716.

13. Jeng CJ, Hsieh YT, Yang CM, et al. Development of diabetic retinopathy after cataract surgery[J]. PLoS ONE. 2018;13(8):e0202347. https://doi.org/10. 1371/journal.pone.0202347.

14. Goyal S, Hardin J, Uwaydat SH, et al. Review and update of cataract surgery in the diabetic eye[J]. Expert Rev Ophthalmol. 2017;12(5):359-71. https://doi.org/10.1080/17469899.2017.1351296.

15. Ikegami Y, Takahashi M, Amino K. Evaluation of choroidal thickness, macular thickness, and aqueous flare after cataract surgery in patients with and without diabetes: a prospective randomized study[J]. BMC Ophthalmol. 2020;20(1):102. https:// doi.org/10.1186/s12886-020-01371-7.

16. Pierru A, Carles M, Gastaud P, et al. Measurement of subfoveal choroidal thickness after cataract surgery in enhanced depth imaging optical coherence tomography[J]. Invest Ophthalmol Vis Sci. 2014;55(8):4967-74. https://doi.org/10.1167/iovs. 14-14172.

17. Torabi H, Sadraei M, Jadidi K, et al. Choroidal thickness changes following cataract surgery in patients with type 2 diabetes mellitus[J]. J Curr Ophthalmol. 2019;31(1):49-54. https://doi.org/10. 1016/j.joco.2018.07.004.

18. Ibrahim T, Goernert P, Rocha G. Intraoperative outcomes and safety of femtosecond laser-assisted cataract surgery: Canadian perspective[J]. Can J Ophthalmol. 2019;54(1):130-5. https://doi.org/10. 1016/j.jcjo.2018.02.022.

19. Palanker DV, Blumenkranz MS, Andersen D, et al. Femtosecond laser-assisted cataract surgery with integrated optical coherence tomography[J]. Sci
Trans Med. 2010;2(58):58ra85. https://doi.org/10. 1126/scitranslmed.3001305.

20. Scott WJ, Tauber S, Gessler JA, et al. Comparison of vitreous loss rates between manual phacoemulsification and femtosecond laser-assisted cataract surgery[J]. J Cataract Refract Surg. 2016;42(7):1003-8. https://doi.org/10.1016/j.jcrs.2016.04.027.

21. Roberts HW, Wagh VK, Sullivan DL, et al. A randomized controlled trial comparing femtosecond laser-assisted cataract surgery versus conventional phacoemulsification surgery[J]. J Cataract Refract Surg. 2019;45(1):11-20. https://doi.org/10.1016/j. jcrs.2018.08.033.

22. Sperl P, Strohmaier C, Kraker H, et al. Intraocular pressure course during the femtosecond laser-assisted cataract surgery in porcine cadaver eyes[J]. Invest Ophthalmol Vis Sci. 2017;58(14):6457-61. https://doi.org/10.1167/iovs.17-21948.

23. Manning S, Barry P, Henry Y, et al. Femtosecond laser-assisted cataract CrossMark surgery versus standard phacoemulsification cataract surgery: study from the European registry of quality outcomes for cataract and refractive surgery[J]. J Cataract Refract Surg. 2016;42(12):1779-90. https://doi.org/10.1016/j.jcrs.2016.10.013.

24. Vujosevic S, Muraca A, Alkabes M, et al. Early microvascular and neural changes in patients with type 1 and type 2 diabetes mellitus without clinical signs of diabetic retinopathy[J]. Retina. 2019;39(3): $435-45$. 0000000000001990.

25. Brito PN, Rosas VM, Coentrao LM, et al. Evaluation of visual acuity, macular status, and subfoveal choroidal thickness changes after cataract surgery in eyes with diabetic retinopathy[J]. Retina. 2015;35(2):294-302. https://doi.org/10.1097/iae. 0000000000000298 .

26. Singh N, Pai SG, John TA. Evaluation of visual outcomes of cataract surgery in diabetic patients and assessment of post-operative complications as compared to non-diabetics[J]. J Clin Diagn Res. 2019;13(3):NC10-4. https://doi.org/10.7860/jcdr/ 2019/37529.12711.

27. Denier C, Fajnkuchen F, Giocanti-Auregan A. Central retinal thickness assessment in a real life setting after cataract surgery in diabetic patients[J]. J Fr Ophtalmol. 2018;41(10):904-9. https://doi.org/10. 1016/j.jfo.2018.03.025.

28. Denniston AK, Chakravarthy U, Zhu H, et al. The UK diabetic retinopathy electronic medical record (UK DR EMR) users group, report 2: real-world data for the impact of cataract surgery on diabetic macular oedema[J]. Br J Ophthalmol. 2017;101(12): 
1673-8. https://doi.org/10.1136/bjophthalmol2016-309838.

29. Pilotto E, Leonardi F, Stefanon G, et al. Early retinal and choroidal OCT and OCT angiography signs of inflammation after uncomplicated cataract surgery[J]. Br J Ophthalmol. 2019;103(7):1001-7. https://doi.org/10.1136/bjophthalmol-2018312461.

30. Braun RD, Wienczewski CA, Abbas A. Erythrocyte flow in choriocapillaris of normal and diabetic rats[J]. Microvasc Res. 2009;77(3):247-55. https:// doi.org/10.1016/j.mvr.2009.02.003.

31. Lains I, Talcott KE, Santos AR, et al. Choroidal thickness in diabetic retinopathy assessed with swept-source optical coherence tomography[J]. Retina. 2018;38(1):173-82.

32. Wang JC, Lains I, Providencia J, et al. Diabetic choroidopathy: choroidal vascular density and volume in diabetic retinopathy with swept-source optical coherence tomography[J]. Am J Ophthalmol. 2017;184:75-83. https://doi.org/10.1016/j.ajo. 2017.09.030.

33. Pierro L, Iuliano L, Cicinelli MV, et al. Retinal neurovascular changes appear earlier in type 2 diabetic patients[J]. Eur J Ophthalmol. 2017;27(3): 346-51. https://doi.org/10.5301/ejo.5000887.

34. Nagy Z, Takacs A, Filkorn $\mathrm{T}$, et al. Initial clinical evaluation of an intraocular femtosecond laser in cataract surgery[J]. J Refract Surg. 2009;25(12): 1053-60. https://doi.org/10.3928/1081597x20091117-04.

35. Asena BS, Karahan E, Kaskaloglu M. Retinal and choroidal thickness after femtosecond laser-assisted and standard phacoemulsification[J]. Clin Ophthalmol. 2017;11:1541-7. https://doi.org/10.2147/ opth.s127792.

36. Crozafon PC, Bouchet C, Zignani M, et al. Comparison of real-world treatment outcomes of femtosecond laser-assisted cataract surgery and phacoemulsification cataract surgery: a retrospective, observational study from an outpatient clinic in France[J]. Eur J Ophthalmol. 2020. https://doi. org/10.1177/1120672120925766.

37. Chen X, Xiao W, Ye S, et al. Efficacy and safety of femtosecond laser-assisted cataract surgery versus conventional phacoemulsification for cataract: a meta-analysis of randomized controlled trials[J]. Sci Rep. 2015. https://doi.org/10.1038/srep13123.

38. Wei Y, Xu L, Song H. Application of Corvis ST to evaluate the effect of femtosecond laser-assisted cataract surgery on corneal biomechanics[J]. Exp
Therapeutic Med. 2017;14(2):1626-32. https://doi. org/10.3892/etm.2017.4675.

39. Conrad-Hengerer I, Al Juburi M, Schultz T, et al. Corneal endothelial cell loss and corneal thickness in conventional compared with femtosecond laserassisted cataract surgery: three-month follow-up[J]. J Cataract Refract Surg. 2013;39(9):1307-13. https:// doi.org/10.1016/j.jcrs.2013.05.033.

40. Cavallini GM, Fornasari E, De Maria M, et al. Bimanual femtosecond laser-assisted cataract surgery compared to standard bimanual phacoemulsification: a case-control study[J]. Eur J Ophthalmol. 2019;29(6):629-35. https://doi.org/10.1177/ 1120672118805323.

41. Kolb CM, Shajari M, Mathys L, et al. Comparison of femtosecond laser-assisted cataract surgery and conventional cataract surgery: a meta-analysis and systematic review[J]. J Cataract Refract Surg. 2020;46(8):1075-85. https://doi.org/10.1097/j.jcrs. 0000000000000228 .

42. Day AC, Burr JM, Bennett K, et al. Femtosecond laser-assisted cataract surgery versus phacoemulsification cataract surgery (FACT) a randomized noninferiority trial[J]. Ophthalmology. 2020;127(8):1012-9. https://doi.org/10.1016/j. ophtha.2020.02.028.

43. Ewe SYP, Abell RG, Oakley CL, et al. A comparative cohort study of visual outcomes in femtosecond laser-assisted versus phacoemulsification cataract surgery[J]. Ophthalmology. 2016;123(1):178-82. https://doi.org/10.1016/j.ophtha.2015.09.026.

44. Day AC, Burr JM, Bennett K, et al. Femtosecond laser-assisted cataract surgery compared with phacoemulsification cataract surgery: randomized noninferiority trial with 1-year outcomes[J]. J Cataract Refract Surg. 2020;46(10):1360-7. https:// doi.org/10.1097/j.jcrs.0000000000000257.

45. Nagy ZZ, Takacs AI, Filkorn T, et al. Complications of femtosecond laser-assisted cataract surgery[J]. J Cataract Refract Surg. 2014;40(1):20-8. https:// doi.org/10.1016/j.jcrs.2013.08.046.

46. Samanta A, Kumar P, Machhua S, et al. Incidence of cystoid macular oedema in diabetic patients after phacoemulsification and free radical link to its pathogenesis[J]. Br J Ophthalmol. 2014;98(9): 1266-72. https://doi.org/10.1136/bjophthalmol2013-304438.

47. Chu CJ, Johnston RL, Buscombe C, et al. Risk factors and incidence of macular edema after cataract surgery a database study of 81984 eyes[J]. Ophthalmology. 2016;123(2):316-23. https://doi.org/ 10.1016/j.ophtha.2015.10.001. 
48. Liu J, Jones RE, Zhao J, et al. Influence of uncomplicated phacoemulsification on central macular thickness in diabetic patients: a meta-analysis[J]. PLoS ONE. 2015;10(5):e0126343. https://doi.org/ 10.1371/journal.pone.0126343.

49. Johannesen SK, Viken JN, Vergmann AS, et al. Optical coherence tomography angiography and microvascular changes in diabetic retinopathy: a systematic review[J]. Acta Ophthalmol. 2019;97(1): 7-14. https://doi.org/10.1111/aos.13859.

50. Romero-Aroca P. Targeting the pathophysiology of diabetic macular edema[J]. Diabetes Care. 2010;33(11):2484-5. https://doi.org/10.2337/dc101580 .

51. Chae JB, Joe SG, Yang SJ, et al. Effect of combined cataract surgery and ranibizumab injection in postoperative macular edema in nonproliferative diabetic retinopathy[J]. Retina- J Retinal Vitreous Dis. 2014;34(1):149-56. https://doi.org/10.1097/ IAE.0b013e3182979b9e.

52. Mittra RA, Borrillo JL, Dev S, et al. Retinopathy progression and visual outcomes after phacoemulsification in patients with diabetes mellitus[J]. Arch Ophthalmol. 2000;118(7):912-7.

53. Vujosevic S, Muraca A, Alkabes M, et al. Early microvascular and neural changes in patients with type 1 and type 2 diabetes mellitus without clinical signs of diabetic retinopathy[J]. Retina (Philadelphia, Pa). 2019;39(3):435-45. https://doi.org/10. 1097/iae.0000000000001990.

54. Ibrahim AM, Elgouhary SM, Nassar MK, et al. Changes in choroidal thickness after cataract surgery[J]. Semin Ophthalmol. 2018;33(5):664-70. https://doi.org/10.1080/08820538.2017.1416410.
55. Yip VCH, Laude A, Tan KA, et al. A longitudinal study of choroidal changes following cataract surgery in patients with diabetes[J]. Diab Vasc Dis Res. 2019;16(4):369-77. https://doi.org/10.1177/ 1479164119841536 .

56. Shahzad R, Siddiqui MAR, Zafar S, et al. Choroidal thickness changes following cataract surgery using swept source optical coherence tomography[J]. Can J Ophthalmol. 2018;53(1):60-4. https://doi.org/10. 1016/j.jcjo.2017.06.019.

57. Falcao MS, Goncalves NM, Freitas-Costa $\mathrm{P}$, et al. Choroidal and macular thickness changes induced by cataract surgery[J]. Clin Ophthalmol. 2014;8: 55-60. https://doi.org/10.2147/opth.S53989.

58. Brito PN, Rosas VM, Coentrao LM, et al. Evaluation of visual acuity, macular status, and subfoveal choroidal thickness changes after cataract surgery in eyes with diabetic retinopathy[J]. Retina-J Retinal Vitreous Dis. 2015;35(2):294-302. https://doi.org/ 10.1097/iae.0000000000000298.

59. Xu H, Chen M, Forrester JV, et al. Cataract surgery induces retinal pro-inflammatory gene expression and protein secretion[J]. Invest Ophthalmol Vis Sci. 2011;52(1):249-55. https://doi.org/10.1167/iovs. $10-6001$.

60. Tso MOM, Shih CY. Experimental macular edema after lens extraction[J]. Invest Ophthalmol Vis Sci. 1977;16(5):381-92.

61. Henderson BA, Kim JY, Ament CS, et al. Clinical pseudophakic cystoid macular edema-risk factors for development and duration after treatment[J]. J Cataract Refract Surg. 2007;33(9):1550-8. https:// doi.org/10.1016/j.jcrs.2007.05.013. 